\title{
Main Schools of Grammar, Grammar in Schools and Pedagogical Grammar
}

\author{
Ahmed Mohammed Saleh Alduais \\ Dept. of English, King Saud University \\ Riyadh, Kingdom of Saudi Arabia
}

Tel: 966-55-136-7-208Ｅ-mail: ibnalduais@yahoo.com

Received: November 1, 2012 Accepted: November 18, 2012 Published: November 20, 2012

doi:10.5296/ijele.v1i1.2720 URL: http://dx.doi.org/10.5296/ijele.v1i1.2720

\begin{abstract}
Purpose: To present theoretically the major schools of grammar in relation to teaching approaches of grammar in schools and using grammar in pedagogy.

Method: Reviewing previous studies and related literature-using analytical analysis to achieve the above mentioned aim of this paper.

Results: Results indicated that the major schools of grammar are: traditional, structural and transformational grammars respectively due to great influence on the field of language study in general and language teaching, learning and pedagogy in particular. Besides, each school of grammar has proved more powerful for teaching certain learner's levels: traditional grammar for non-native speakers, structural grammar for native speakers, and transformational grammar for advanced level learners in both cases native and non-native speakers.

Conclusions: This study is concluded with that each and every approach of the three introduced major schools of grammar has its strengths and weaknesses and that is why a new approach that could be called pedagogical grammar has to be initiated and launched by teacher educators.
\end{abstract}

Keywords: grammar, major schools of grammar, traditional grammar, structural grammar, transformational grammar, grammar in schools, pedagogical grammar 


\section{Introduction}

I still remember when I was a secondary school pupil studying English in the school. The main point is that, once I came late and I was knocking the door the teacher said that who is knocking the door. Pretending that I can speak English, I had answered "it is me". But he replied quickly "say it is I" and NOT 'me'. He didn't tell me and my classmates as well why we should use 'I' but not 'me'. More interestingly and later on, when I had joined the university, the same thing has happened to me again with the professor of grammar courses, but this time it is a little bit different. He was (the professor) talking about the history of English grammar and he has raised the question that what is the difference between "it is me" and 'it is I" and which of which is the correct one. Very proudly, I raised my hand and told him that the former but not the latter is the correct one. Unfortunately, I was not right as he clarified later because both are correct from the point of view of different schools of grammar. Thus, these two events have meant nothing to me, but after I have graduated and read more about grammar they do mean a lot to me.

Strictly speaking, since the time of Greek, Latin and Roman scholars, grammar has been taught in the schools. Since that time, however, grammar has passed through many developments, changes and modifications. Grammars of language, mainly English language have started as Latin-like and Greek-like. This influence of the Latin grammar on the English grammar has last for a long time. It was only in the late of the $19^{\text {th }}$ onward, English grammar has started a new path if not paths, different from the Latin path. For one reason or another English has become the international language, a language that is used world-widely. For that matter it is taught nearly in a major number of the countries as a main subject in Schools. The point, however, is how this subject is taught? What are the methodologies which are followed for teaching it?

Coming back to types of grammar, actually many schools of grammar which were unsatisfied with the Latinized English grammar, have revolted against this school of grammar, they thought, such a type of grammar (they mean Latin) is not suitable to be used to describe English language. What is interesting here is that the process of reacting or revolting against a particular school will be activated, many schools have appeared, each of which will not only criticize the Latinized grammar of English as the earliest school, but this and the schools that have appeared after it. In spite of this, it is actually impossible to mention all these schools in this term-paper. This is because not all of them have a great influence on the process of teaching and pedagogy. That is, some of these schools which have proved great influence will be the concern of this term-paper.

Hence the main question of this paper is which type of grammar from among the main schools of grammar (traditional, structural and transformational grammar(s)) is the more effective one for pedagogical purposes? The researcher is going to provide a number of the conducted studies on all these main types of grammar and attempt critically to state the answer of the raised question. Basically, this paper is three-folded: the researcher will start presenting critically a number of the definitions of grammar, then introducing precisely and comparatively the main schools of grammar and the last part of this essay is a number of the conducted studies which either test the effectiveness of the main schools of grammar on 
pedagogy or promote in one way or another for a particular school of grammar to be used as a method of teaching.

\section{Definitions of Grammar}

It is totally agreed by most of the world linguists and language specialist that any language has its own grammar which in one way or another entirely different from the grammar of another language. Some grammarians have tried to classify language on the bases of some grammatical features such as inflectional and non-inflectional grammars. On the other hand, it is only partially agreed by most of the linguists and grammarians world-widely, when it comes to defining grammar or deciding what does the term 'grammar' refer to. Nevertheless, even if we consider the common elements and indications from among huge number of definitions of grammar, we will face another problem which is how this grammar should be taught and how it should be analyzed and interpreted? Because of this last point many schools of grammar have appeared, each of which have viewed grammar according to their provided evidences and explanations. To make it clear, the following are a number of the definitions of grammar which will indicate what has been mentioned above:

Grammar is a central term in LINGUISTICS, but one which covers a wide range of phenomena. Several types of grammar can be distinguished... descriptive grammar... theoretical (formal)... comparative... traditional... competence grammar... performance and universal grammar. (Crystal, 1997: pp 174-5)

A description of the structure of a language and the way in which linguistic units such as words and phrases are combined to produce sentences in the language... usually takes into account the meanings and functions these sentences have in the overall system of the language... may or may not include the description of the sounds of a language. (Richards, 1992: pp 161)

Grammar commonly denotes a level or component of language subsumed under the general level of form... distinct from meaning and sound, specifically the words, phrases and clauses of which sentences are composed. Grammar itself can be subdivided into SYNTAX... and MORPHOLOGY... (Wales, 2001: p. 179)

Grammar is a protean term, meaning different things to different people... part of philosophy... art of writing... an object of study... usually synonymous with inflection ad syntax...the grammar typically presented in the context of language teaching and learning... description of grammatical rules... grammar books and a property of mind tacit knowledge... (Helen \& Keith, 1998: pp. 143-5)

... Grammar can refer to a variety of phenomena... among grammarians, there is considerable disagreement concerning its nature, discussions of grammar fall within three main areas: social 'what is to be regarded as standard grammar and what is the status and role of other varieties, pedagogical 'how is grammar learnt and how it should it be taught', and linguistic 'what is grammar and how does it work... (Byram, 2004: p. 248)

In modern linguistics 'grammar' has a broader meaning than in the traditional usage 'we use it with a systematic ambiguity. On the one hand, it refers to the 
explicit theory constructed by the linguist and proposed as a description of the speaker's competence'... it means the speaker's knowledge of a language which includes sound, meaning and syntax. (Ambrose-Grillet, 1978: p. 52)

In Oxford International Encyclopedia (2003), grammar is presented in terms of two particular approaches 'functionalism' and 'formalism' or functional [cognitive and social perspectives] and formal grammars.

If we look at the above definitions, we can notice the following points:

1. They all agree in one way or another that 'grammar' can be defined in many ways and to mean different things;

2. Not all of them consider grammar in terms of teaching and learning it, instead they view it technically;

3. Among all the above mentioned definitions, Byram's one at least in my opinion seems the most comprehensive one for a couple of reasons;

4. It views grammar not only technically as a system that studies the features of language as in the case of other definitions but also socially, pedagogically and linguistically;

5. It serves in improving the main idea of this term-paper which is what is grammar, how it is learnt and how it is taught.

Having mentioned a number of the general definitions of grammar, we now look at some definitions which are more accurate. Among these definitions of grammar are those introduced by (Hartwell, 1985: pp. 109- 120), Grammar 1 "a set of formal patterns in which the words are arranged in order to convey larger meanings", Grammar 2 is a "branch of linguistic science... concerned with the description analysis and formulization of formal language patterns", Grammar 3 "etiquette grammar", Grammar 5 "common schools of grammar, internalized grammar" and Grammar 5 "stylistic grammar".

Similar to Hartwell is McClure (2006: pp. 2-3) who presents also four types of grammar but look different from those which have been discussed by Hartwell. According to him, Grammar 1 is "teachers' or schools' grammar (traditional grammar, prescriptive)", Grammar 2 is "phrase structure grammar (descriptive grammar)", Grammar 3 is "transformational generative grammar (from surface structures to deep structures)", Grammar 4 is "cognitive grammar (explains language through processes that occur in the brain". McClure (ibid) continues quoting from Williams that grammar is "nothing more than a system for describing the patterns of regularity that are inherent in language". If we compare Williams' four grammars with Hartwell's five grammars, will firstly decide that they are different. Yet, it is true that they are apparently different but their purposes and their core ideas are to a great extent similar to each other. Regardless of the idea that Hartwell has presented five types of grammar and Williams has presented only four types but one of Hartwell's grammars, Grammar 3 "etiquette grammar" cannot be considered fully as a type of grammar, it is a matter of usage rather than system as in the other types of grammar, (McClure, ibid: p. 110).

\section{Major Schools of Grammar}

After we have presented a number of both general and specific definitions of grammar, we now move to the second part of this paper which is discussing briefly but comparatively the 
main types of grammar or the main schools of grammar as it is mentioned in the title of this term-paper. First, it is worthy to mention that Traditional, Structural and Transformational Generative Grammars has been determined as the main schools of grammar due to some studies made by some scholars and researchers who have mentioned these schools as the main ones. Among these researches and books are Rome's Research (2004: p. 1) and LaPalombara's (1976).

Certainly, traditional, structural and transformational grammars are not alike. They may share the apparent idea that they all analyze and search in the grammar of language but each one them has different tools, different methods and different principles in analyzing and presenting the grammar of the English language. Again, these three schools of grammar have entirely different implications regarding the teaching learning grammar. That is some of these schools such as transformational grammar may not have direct methods and principles regarding teaching and learning methods but some implications and methods can be inferred. On the other hand, a school such as traditional grammar has direct methods of teaching and learning grammar.

Tradition grammar is usually referred to "the grammars written by classical Greek scholars, the Roman grammars largely derived from the Greek, the speculative work of the medievals, and the prescriptive approach of the eighteenth-century grammarians", (Malmkjær, 2006: p. 643). Structural grammar, on the other hand is referred to "any approach to the analysis of language that pays explicit attention to the way in which linguistic features can be described in terms of structures and systems", (Crystal, 1997: p. 366). Yet, transformational grammar is referred to the theory which has been developed by Chomsky since the 1950s till now, (Helen \& Keith, 1998).

All Samuel Johnson, Robert Lowth and Murray and some other scholars and linguists are considered as originators of prescriptive traditional grammar (a copy of the Greek and Latin grammars). For Structural grammar Bloomfield, Priestly and other linguists are responsible for making the bases of the structural school. Regarding, the transformational school it was developed by Chomsky and still it is now being developed by him, (LaPalombara, 1976).

Whereas 'most traditional 'school' grammars begin by defining and classifying English words into parts-of-speech categories, and proceed from there to more inclusive sentences components until they arrive at a discussion of the sentence itself", (LaPalombara, ibid: p. 23); structural grammar begins "with an analysis of the sounds of the language in general, and then goes on to isolate mutually exclusive groups of sounds which have semantic significance, the phonemes,... then to the word structure... finally the phrase structure, or syntax, of English... ways in which words can be combined to produce grammatical English sentences", (LaPalombara, 1976: p. 104). The last type, transformational grammar is "a set of rules that defines the unlimited number of sentences of the language and associates each with an appropriate grammatical description", (Malmkjær, 2006: p. 218).

One more difference among these schools can be explained in term of the terminology they make use of. That is, traditional grammarians make use of terms such as 'subject, object, and complement, singular and plural". Unlike them are structural grammarians who make use of terms such as "phonemes. Morphemes", and so are the transformational grammarians who make use of terms quoted form mathematics and symbolic logic such as transformations, 
generate, and generative, (LaPalombara, ibid: p. 216).

Moreover, Thornbury (1999) makes a distinction between traditional grammar and structural grammar form the point of view of teaching methods. He describes the former as prescriptive and the latter as descriptive. He goes on to distinguish between teaching grammar deductively and teaching it inductively. Similar to this comparison is the one made by Yule (2006) who introduces the prescriptive traditional grammar as a prescription of how grammar should be used, and structural grammar as a description of how grammar is used. For transformational grammar, he states (Yule) it is the process of generating infinite number of sentences form a finite number of rules.

Furthermore, Swan (2005) makes a distinction between these three schools in terms of formal approaches to grammar and functional approaches to grammar. Whereas generative grammar is considered as a formal grammar which concentrates more on syntax rather than other linguistic branches, structural and traditional grammars are considered as functional grammars, 'accounts for the structure of language in terms of the functions it has to perform', (ibid: p. 19). He agrees to the above opinions also that traditional grammar is the prescriptive one and structural grammas is the descriptive one, while transformational is the mental grammar or "grammar in the head" as he calls it, (ibid: pp. 66-72).

Characteristically, each one of these schools of grammar has been influenced by some earlier schools such the traditional prescriptive school influenced by the Greek and Latin traditional school. Similarly, transformational school has been greatly influenced by other fields such as logic, mathematics and psychology, (Bierwisch, 1971: p. 75).

More interestingly in the schools of grammar is the process of the continuity of revolting against one another. Put it another way, traditional school of grammar may the only one that have evolved and rose as an imitation for the classical grammars of Greek and Latin languages. Dissimilarly, structural grammar started as a reaction to the traditional approach claiming that such an approach is not suitable for a language such as English, (Lehmann, 1972). Lehmann goes on, transformational grammar started as a reaction against both traditional and structural grammars. Doubtless to say and according to a huge number of the studies transformational grammar has proved more accurate and logic than other types of grammar, (Thakur2001, Allen \& Buren, 1971, Piattelli-Palmarini, 1980).

Needless to say, each one of these schools of grammar has its strong and weak spots. That is to say, each of which may have succeeded to achieve some goals that serve in the study of language and yet have failed to achieve some other goals. For instance, none can deny the advantage of traditional grammar in introducing nearly all the basic concepts and terminology of grammar, yet it is attacked by structuralists, transformationalists and other grammarians and theorists for being normative in nature, prescriptive "based largely on intuitions", (Malmkjær, 2006: p. 643). Structural grammar, on the other hand, is criticized by Chomsky and other linguists for being insufficient and inadequate for wholly depending on 'wrong assumptions" in "data-gathering techniques", (LaPalombara, 1976: p. 209). Just like both prescriptive (traditional) and descriptive (structural) grammars have been criticized and have their some spots of weakness transformational grammar does also have been attacked and does have some spots of weakness. Accuracy and innovativeness are to be considered as two elements that can interpret the success of this type of grammar over the other types of 
grammar. Yet, it is criticized for being sentence-based, it "proved inadequate for generating a whole text", (Helen and Keith, 1998).

\section{Grammar in Schools}

Have introduced briefly and comparatively the main schools of grammar, we now move to a deeper point in this paper which is grammar in schools. As a matter of fact, traditional school grammar is no doubt the most influential and used one in Schools. It is a truth that grammar of English has started to be taught traditionally and prescriptively. That is to say, not until the late $19^{\text {th }}$ century and the beginning of the 20 century other approaches of teaching grammar have been launched and appeared as competitive to traditional approach. Furthermore, whether English was taught for native speakers or non-native speakers, traditional approach was dominating and still dominating on the methods of teaching and text-books of grammar. Even teachers who have been influenced by other schools of grammar and are being convinced by the limitations and inappropriateness of the traditional school, they are still using it because they feel that such alternative approaches are inadequate to fulfill completely their teaching purposes. The following studies will show how one approach is suitable for particular purposes and levels of teaching and on the other hand unsuitable for some other purposes and levels as well.

Chen (2004) has conducted a research arguing against the use of traditional grammar for improving the students' language skills in the college level. He assumed that using a cooperative learning approach rather than the traditional grammar translation method will show a great difference at the level of the freshmen students, both males and females. $\mathrm{He}$ concludes his study proving that the experimental group who has been taught by his proposed approach has proved more competent and improved than the controlled group who has been taught using the traditional grammar.

Testing the effects of an innovative approach to writing pedagogy on second language writing accuracy was the main aim of a study conducted by Hartshorn (2008). He has hypothesized that teaching students to improve their writing skill with the use of an innovative approach rather than the traditional approach will improve their writing skill and raise their awareness to correcting errors. He ends his study with that students in the controlled group taught with the use of traditional approach show less awareness and improvement of their writing skill. On the other hand, students of the treatment group, taught with the use of the innovative approach have proved more awareness and improvement in their writing skill.

One more study is conducted by Mitchell (1996) who theoretically, analytically and critically presents to us some controversial issues in grammar teaching, learning and composing. He claims that the main aims of studying grammar by linguists were not only linguistics ones, there are also social and pedagogical aims as he stated. It is clear that his claim is similar to Byram's definition of grammar who as has been mentioned earlier, has introduced grammar form three angles: linguistic, social and pedagogical.

Attempting to explain and prove the influence of the Latin, Greek and Roman grammars on the early English grammar, Stone (1995) conducted his/her thesis. S/he proposed that early English grammar was being Latinized and teaching grammar in the British schools as well. It is 
shown also how traditional school of grammar has risen and has become the most influential school.

Additionally, McClure (2006), in his study discusses analytically and critically the role of grammar teaching on improving the students' abilities in writing skill in particular and other skills in general. He reviews a large a number of the definitions of grammar including scholars such as Hartwell and Williams. Then, he turns to present some of the teachers' definitions who were participants in his study. More importantly, he lists nearly 12 reasons for why teachers of English tend to teach grammar rules even in writing classes. According to his findings, they may lack the skill of research and yet they believe grammar is everything in learning and teaching a language. His study is concluded with that though some teachers were satisfied with teaching grammar in context rather than as rules to be memorized (traditional grammar) but they say it wastes their time and they usually do not find time to correct assignments which make them prefer the traditional approach.

One more study is conducted by Eanes (1998) who unlike studies that have been mentioned above argues in favor of that traditional grammar must be the approach that should be taught till another approach proves more adequate than it. He maintains that though other schools of grammar such as structural and transformational schools have served in teaching and learning the grammar of English language but in a very limited way. Eanes lists a number of the results of the conducted studies proving that some of them did not show any difference whether using traditional grammar, structural or transformational grammar. For instance and according to him, a study was conducted testing the effects of these schools (traditional, structural and transformational) on the students' abilities to develop simple sentences into complex ones. The results have shown no difference as the researcher of this study concluded.

In addition to what have been mentioned above is Kim's study (2001) who comparatively and analytically introduces the advantages of using both prescriptive grammars and descriptive ones for developing the students' skill of writing. He assumes that teaching grammar a long with concentrating on the content of the produced texts by the second language learners will no doubt help them to develop their English. He showed how some schools revolting against traditional school will claim the uselessness of teaching grammar rules and affect on the content of the produced texts and also their meanings. In spite of this, Kim states that at least in his study, students have shown that they need to learn grammar rules in order to help them improve the form of their writings because they need to develop both form and content.

Moreover, McClay (1988) conducted a study investigating the student teachers' attitudes about grammar learning and teaching as well. The study did not determine any approach or school of grammar, grammar was generally discussed. The results show that those fresh teachers of English lack the basic knowledge of what grammar is. Yet, they show negative attitudes towards teaching and learning of grammar. McClay believes that grammar is no doubt a needed element for learning and teaching language but in the appropriate ways.

\section{Pedagogical Grammar}

Having introduced grammar in general, the main schools of grammar and grammar in schools, the final part in this term-paper is pedagogical grammar. One might curiously ask, what is the difference between grammar in schools and pedagogical grammar or grammar pedagogy? 
Simply, grammar in schools has been discussed to show some attitudes towards the use of the main schools of grammar and which of which is more appropriate for pedagogical purposes. However in this part, we are going to state what is exactly meant by pedagogical grammar and why do we need a new approach of grammar called as pedagogical grammar?

Odlin (2006) states pedagogical grammar "usually denotes the types of grammatical analysis and instruction designed for the needs of second language students", (p. 1). Odlin suggests that we need a pedagogical grammar because prescriptive grammar fails to meet the teaching purposes in the case of the first language speakers, just like descriptive and generative grammar fails to achieve the teaching purposes for second language learners, (ibid: pp. 1-10).

Abushibab (2008) conducted a study testing the possibility of using transformational generative grammar for pedagogical purposes. He introduces transformational generative grammar along with structural grammar. He first shows how TGG has some advantages on structural grammar "in interpreting sentences of the same patterns", (ibid: p. 12). He concludes his study maintaining that TGG "is not concerned with English teaching methodology... no teaching procedures of transformational grammar that can be converted into teaching procedures, but it gives implicit assumptions about language teaching...we can deal with...to derive some teaching English methodology", (ibid).

Again, Hunter (1996) in his research article states clearly the need for a better grammar, a grammar that is pedagogical. He presents a number of the studies proving that traditional grammar is "inaccurate", and structural and transformational grammars are scientific grammars and technical; they are to be used for research purposes and theoretical purposes rather than teaching purposes, Hunter, 1996: p. 1-11). He declares that by pedagogical grammar we mean grammar that is intended for only teaching purposes mainly writing teaching. In spite of this, Hunter, then, mentions as one of the results of the studies which he has included in his article that transformational grammar has proved more adequate than traditional grammar especially in teaching advanced courses of writing, such as developing simple, complex and compound sentences.

Furthermore, Strauss, Ahn, Lee and Park (n. d.) promote for a new approach of grammar which is basically pedagogical but they choose to call it conceptual grammar. They start their research by stating that their approach is "non-traditional", (p. 1). Yet, at the end of their research they came up with the result that we need to teach in both methods deductively and inductively, but we don't need to teach grammar prescriptively especially for advanced no-native learners and teachers. They conducted their study on a Korean community.

Once again, Rome (2004) declares interrogatively that traditional grammar is still used though most of the teachers are being convinced by its insufficiency especially when used for teaching writing and composition. He maintains that transformational grammar has proved better in such a case. He concludes that we need a pedagogical approach that is meant only for scholastic purposes.

Obviously, it seems that a large number of the linguists, teachers, grammarians and researchers are agreeing that traditional grammar has proved inadequate and limited namely in teaching writing curses. Yet, it is still world-widely used as a method of teaching writing in many schools where in English is taught as second language or foreign language. Ming (2004) 
states in his article that the revolution of technology and computer programs have no doubt lead to the breakdown of traditional grammar and the appearance of new schools of grammar. He insists o his article that traditional grammar has become rarely used after the technology revolution.

Folse (2006) argues in favor of that we need to teach our students not only grammatical rules or the use of these rules, but also some theoretical information about them. In other words, we have to balance between theory and rule, practical and theoretical knowledge. Folse ends his research paper with that we need a pedagogical approach of grammar that makes our students and teachers as well keenly competent not only in memorizing rules, but also in knowing the functions of these rules and at least the basic knowledge of theories of grammar.

Dryer (n. d.) makes a distinction between the main schools of grammar in terms of explanation and description. While structural grammar is determined as descriptive both traditional and transformational grammars are considered as explanatory ones. His indications may indicate that there is a difference between describing the language and stating or explain why it appears in the form it is appears in it.

Furthermore, F. \& J Aarts state that pedagogical grammars "serve in a different purpose... enable foreign students to learn the language rather than to provide insight into questions of a theoretical nature... supply information about the facts without offering detailed explanations of why these facts are as they are", (1982: p. 1). They add "pedagogical grammars play an important part in the student's linguistic education", (ibid). Such a thing however, is entirely different from what has been mentioned by Folse who introduced pedagogical grammar as a balanced approach between theoretical knowledge and practical and effective learning of language.

Although some scholars and linguists have made some attempts to make transformational grammar for pedagogical purposes as it has been mentioned above, but some others will clearly state that one feature of the transformational grammar is no being pedagogical. It is "a purely linguistic one, which is not meant to be taught to beginners learning foreign language", Al-Khuli (1979: p. 17).

Warschauer and Kern (2006) promote for a net-work-based teaching from the point of view of three perspectives: structural (Bloomfield), cognitive (Chomskyan grammar) and socio-cognitive (Halliday). They show how using computers for pedagogical purposes in teaching grammar can solve the problems that main schools of grammar have failed to achieve. They quote from Crook three metaphors indicating the great help of computers in learning and teaching: "computer-as-tutor", "computer-as-pupil" and "computer-as-tool", (ibid: p. 7).

Norton \& Toohey (2006) argues in favor of that grammar teaching and learning are greatly affected by critical pedagogies. They mean by critical pedagogies some social and political effects that can either directly or indirectly take part in developing the process of language learning for both second and foreign language learners of English. In an interesting way, Nunan (2006) raises the questions:

Why does Teacher A teach functions but not structures? Why does Teacher B try to encourage learners to discover their own errors rather than correcting the 
learners herself? Why does Teacher C try to develop communication skills through role play, language games and so on, rather than through drills and controlled practice activities? Why does Teacher D create all her own materials through authentic sources, while Teacher E, who has students with similar needs, uses course books written by someone else?

By such questions Nunan wants in one way or another to show that we may sometimes need to choose the particular approach that suits the level of our students and our teaching purposes but in some case some teachers are just using this or that particular approach because he or she has studied it or liked it which is actually not the right way of teaching. He concludes that grammar curricula in particular and English language curricula in general must be designed to suite the teaching purposes.

\section{Conclusion}

This paper aimed at introducing the main schools of grammar, grammar in schools and pedagogical grammar. It has been shown that traditional, structural and transformational generative grammars are the main schools of grammar for a number of reasons. Among these reasons and the most important is the great influence of these schools of grammar in the fields of language study, language teaching and methodology and more importantly the study of linguistics in general. Traditionalists approach language and its grammar starting with words and then moving to phrases, ending with the sentence. Unlike traditionalists, structuralists start with sounds and then move to larger linguistic elements till they reach to the sentence level. Transformationalists start with sentence moving down till they reach the sound. It has been also shown that traditional grammarians or prescriptivists have been greatly influenced by Greek, Latin and Roman grammars and they contribute in their grammar in giving the basic terms of grammar which are still used till today. Descriptivist grammarians use different terminology such as morphs phonemes, etc. Yet, transformational grammarians have brought some terms quoted from mathematics and symbolic logic such as generate, node and transformations.

More importantly, it has been argued that each type of the main schools of grammar can be used for pedagogical purposes according to the level of the students and their goals of learning the language. That is, traditional grammar has proved and still proving valuable for both native and non-naïve speakers of English language. In spite of this, some others have argued in favor of that traditional grammar is useful and valuable in the case of non-native speakers and learners but not for native-speakers. They would suggest structural (descriptive) grammar for native-speakers learners. It has been also agreed by most of the mentioned studies and researches above that both structural and traditional grammar fail to some extent in achieving some teaching purposes mainly in advanced levels and specialized course such as advanced writing in particular and advanced courses in grammar in general. Alternatively, transformational generative grammar can be used for pedagogical purposes in advanced levels such as writing courses or advanced grammar courses. That is, transformational generative grammar and structural grammar are technical and scientific which limit their use for pedagogical purposes.

The paper is concluded with that we need an approach that brings these main schools all 
together. That is, an approach where we can decide which for who. An approach that balances between theoretical and practical knowledge of grammar and that is why we would call it as pedagogical grammar approach.

\section{References}

AArts, F., \& J. (1982). English Syntactic Strucutres: Functions and categories in sentence analysis. Oxford. New York. Toronto. Sydney. Paris. Frankfort. and Bohn, Scheltema \& Holkema Utrecht. Antwerp: Pergamon Press.

ABUSHIBAB, İ. (2008). CAN TRANSFORMATIONAL GENERATIVE GRAMMAR BE USED FOR PEDAGOGICAL PURPOSES? Retrieved from http://search.epnet.com accessed at 20/04/2009

Al-Khuli, M. A. (1979). A contrastive Transformational Grammar: Arabic and Englsih (G. F. Pijper, Ed.). Belgium: Lieden, E. J. Brill.

Allen, J. P. (Ed.). (1971). Chomsky: Selected Readings. London, New York, Toronto: Oxford Uinverstiy Press.

Ambrose-Grillet, J. (1978). Glossary of Transformational Grammar. Rowley, Mass: Newbury House Publishers, Inc.

Bierwisch, M. (1971). Modern Linguistics. The Hague. Paris : Mouton.

Byram, M. (Ed.). (2004). Routledge Encylopedia of Language Teaching and Learning. London and New York: Routledge Taylor \& Francis Group.

Chen, M.-1. (2004). A study of the Effects of Cooperative Learning Strategies on Student Achievement in English as a Foreign Language in a Taiwan College. A dissertation, Doctor of Philosphy in Education: The School of Education, Spalding University. Retrieved from http://proquest.umi.com/login, Retrieved at 05/05/09

Crystal, D. (1997). A Dictionary of Linguistics and Phonetics (4th ed.). Blackwell: Blackwell Publishing.

Dryer, M. S. (n.d). Descriptive Theories, Explanatory Theories, and Basic Linguistic Theory1. Retrieved from http://linguistics.buffalo.edu/people/faculty/dryer/dryer/desc.expl.theories.pdf (20/04/2009).

Eanes, L. M. (Fall Semester, 1998). Teaching Grammar to Community College Students Using Model Writing and Student Writing. A thesis, Master of Arts: George Mason University Fairfax, Virginia. Retrieved from http://proquest.umi.com/login (05/05/09).

Folse, K. S. (2006). PEDAGOGICAL GRAMMAR COURSES OFFERED BY MATESOL PROGRAMS IN FLORIDA. Sunshine State TESOL Journal, 1-12.

Harshom, K. J. (July, 2008). The Effects of Manageable Corrective Feedback on ESL Writing Accuracy. A dissertation, Doctor of Philosophy: Brigham Young University. Retrieved from http://proquest.umi.com/login (05/05/09).

Hartwell, P. (Feb., 1985). Grammar, Grammars, and the Teaching of Grammar. College English , 47(2), 105-127.

Hunter, A. D. (1996). Article on Research That Supports the Hunter Writing System: Sentence Sense Text*: A New Grammar That Has Clearly Improved Writing1. *This is the 
mostly unabridged edition of my English Journal article (85, No.7 [Nov., 1996], 102-107), which the editors had to shorten slightly. National Council of Teachers of English.

Johnson, K. (Ed.). (1998). Encylopedic Dictionary of Applied Linguisitcs. Blackwell: Blackwell Publishing.

Kim, E.-Y. (August, 2001). Effects of Grammar Emphasis on the Revising processes of ESL Students: Two Case Studies. A dissertation, Doctor of Philosophy: Northern Illinois University. Retrieved from http://proquest.umi.com/login (05/05/09).

LaPalombara, L. E. (1976). An Introduction to Grammar: Traditional, Structural, Transformational. Cambridge, Massachusetts: Winthrop Publishers, Inc.

Lehmann, W. P. (1972). Descriptive Linguistics: An Introduction (2 ed.). New York: Random House.

Malmkjær, K. (Ed.). (2006). The LINGUISTICS ENCYCLOPEDIA. London and New York: Taylor \& Francis Group, Routledge.

McClay, J. K. (Fall, 1988). Learning and teaching Grammar: The Experiences and Intentions of Student Teachers. A thesis, Master of Education: Edmonton, Alberta. Retrieved from http://proquest.umi.com/login (05/05/09).

McClure, E. S. (2006). SIX MIDDLE SCHOOL ENGLISH LANGUAGE ARTS TEACHERS' BELIEFS ABOUT GRAMMAR AND THEIR TEACHING OF GRAMMAR WHILE PARTICIPATING IN A PROFESSIONAL LEARNING COMMUNITY. A dissertation, Doctor of Philosophy: College of Education Georgia State University. Retrieved from http://proquest.umi.com/login (05/05/09).

Ming, V. T. (March 17 - March 23, 2004). The Death of the Art of Writing: Myth or Reality? When it comes to writing, the next generation is all thumbs. Ubiquity, 5(4), 1-3.

Mitchell, L. C. (May, 1996). Controversies over Grammar: Cotexts and Purposes in the Seventeenth and eighteenth Centuries. A dissertation, Doctor of Philosophy : Faculty of the Graduate School, University of Southern California. Retrieved from http://proquest.umi.com/login (05/05/09).

Norton, B. (Ed.). (2006). Critical Pedagogies and Language Learning. Cambridge: Cambridge University Press.

Nunan, D. (2006). The Learner-Centred Curriculum: A study in Second Language Teaching. Cambridge : Cambridge university Press.

Odlin, T. (Ed.). (2006). Perspectives on Pedagogical Grammar. Cambridge: Cambridge University Press.

Oxford University. (2003). International Encyclopedia of Linguistics (Vol. 4). Oxford: Oxford University Press.

Piattelli-Palmarini, M. (Ed.). (1980). Language and Learning: The Debate between Jean Piaget and Noam Chomsky. Cambridge, Massachusetts, Harvard University Press.

Richards, J. C. (1992). Longman Dictionary of Language Teaching and Applied Linguistics. Longman: Longman University Press.

Rome, J. A. (11/14/2004). Grammar Pedagogy: A summary. 1-2 Retrieved from atlvista.com $(05 / 05 / 09)$. 
Stone, J. (November, 1995). The Common-law Model for Standard English In Johnson's Dictionary. A thesis, Master of Arts: McGill University. Retrieved from http://proquest.umi.com/login (05/05/09).

Susan Strauss, K. A. (n.d). Pedagogical Approaches to Grammar through the Multiple Lenses of Corpus, Discourse Analysis, and Cognitive Linguistics, A workshop papers. Retrieved from atlvista.com (05/05/09). Pennsylvania: The Pennsylvania State University and CALPER.

Swan, M. (2005). Grammar: Oxford Introductions to Language Study (H. G. Widdowson, Ed.). Oxford: Oxford University Press.

Thakur, D. (2001). Syntax. Thakurbari Road, Kadamkuan, Patna 800 003: Bharati Bhawan (publishers \& Distributers).

Thornbury, S. (1999). How to Teach Grammar (J. Harmer, Ed.). Longman: Pearson Education Limited.

Wales, K. (2001). A Dictionalry of Stylistics. London, New York, Reading, San Francisco: Pearson Education Longman.

Warschauer, M. (Ed.). (2006). Network-based Language Teaching: Concepts and Practice. Cambridge: Cambridge university press.

Yule, G. (2006). The Study of Language (3 ed.). Cambridge: Cambridge University Press.

\section{Copyright Disclaimer}

Copyright reserved by the author(s).

This article is an open-access article distributed under the terms and conditions of the Creative Commons Attribution license (http://creativecommons.org/licenses/by/3.0/). 